\title{
Transurethral resection of prostate - a five year experience in College of Medical Sciences and Teaching Hospital,Bharatpur, Nepal
}

\section{A.Agarwal, ${ }^{1}$ G. Sigdel, ${ }^{1}$ N.Lamichhane,,${ }^{1}$ WK. Belokar, ${ }^{2}$}

${ }^{1}$ Mch Resident ${ }^{2}$ Professor and HOD, Department of Urology, CMS-TH Bharatpur, Nepal

\section{Abstract}

\section{Aims}

Transurethral resection of prostate(TURP) is still considered gold standard for the management of benign prostatic hyperplasia(BPH) and it has become the need of every urology center today. The purpose of this study is to report a five years experience and results in the management of BPH by TURP.

\section{Materials and methods}

Retrospective analysis of 330 cases of TURP done by single surgeon between January 2007 and December 2011 in urology unit, College of Medical Sciences, Bharatpur, Nepal was carried out.

\section{Results}

Mean age and duration of symptoms was $64.88 \pm 3.904$ years and 30.7 months respectively, mean size of prostate was $48.33 \pm 15.214$ grams, mean IPSS before surgery was $27.88 \pm 3.493$ and after 1 year follow up of 262 cases it was $9.71 \pm 3.820$. . Mean duration of post operative per urethral catheterization, bladder irrigation with normal saline and total duration of hospital stay was $2.82 \pm 0.622,28.16 \pm 8.895$ and $3.82 \pm 0.622$ days respectively. Mean operating time was $40.53 \pm 12.949$ minutes. $7(2.12 \%)$ patients developed intraperitoneal fluid extravasation, $8(2.42 \%)$ cases developed clot retention. $2(0.67 \%)$ cases re-admitted one week after discharge with clot retention and UTI. 3(0.9\%)cases presented two years after surgery with bladder neck contracture. No case of TUR syndrome was seen and there was no mortality.

\section{Conclusion}

Most of the patients presents late with marked obstructive symptoms and large prostate glands in this part of Nepal. The urinary symptoms in patients with BPH significantly improved after TURP and those patients having severe symptoms gained the most. The complication rates following TURP decreases as experience grow and after a experience of 50 TURP they are almost none. So 50 TURP can be set as benchmark for the beginners. It was also noticed that resection volume of the prostate increased and the resection time decreased significantly after 50 case of TURP.

\section{Key words: BPH, experience, TURP}

Correspondence: Dr. Aman Agarawal

E-mail: draaman@gmail.com 
A Agarwal et al. Transurethral resection of prostate - a five year experience.

\section{Introduction}

The prostate is a fibromuscular organ in males present just below the bladder and above the urogenital diaphragm and normally weighs around 20 grams. ${ }^{1}$ Benign prostatic Hyperplasia (BPH) develops from the periurethral transitional zone whereas prostatic carcinoma from the posterior lobe, a part of the posterior zone. ${ }^{2}$ Patients present with complaints of hesitancy, poor flow, intermittent stream, dribbling, sensation of poor bladder emptying, episodes of near retention, frequency, nocturia, urgency, urge incontinence and nocturnal incontinence.

5-á reductase inhibitor and á-adrenergic blockers are the mainstay medications for the treatment of $\mathrm{BPH}$. Surgical treatment is indicated in failed medical treatment, recurrent urinary tract infection, haematuria, upper urinary tract changes, vesical calculus and acute urinary retention. Traditionally prostatic adenoma can be approached (i) transurethrally (TURP), (ii) retropubically (iii) through the bladder (Transvesical Prostatectomy(TVP). Open prostatectomy is preferred when the size of the prostate is more than 100 grams or in conditions when the patient cannot be positioned in dorsal lithotomy position for TURP. ${ }^{2}$

TURP is one of the most important minimally invasive innovations in urosurgery since its inception 80 years back and many urosurgeons regard it to be the gold standard for treatment of BPH. ${ }^{3}$ In TURP, a singlehand-held rigid lens endoscope, illuminated by fiberoptic light source, under video control is advanced through the penile urethra and strips of prostatic tissue are cut from bladder neck to verumontanum, using high frequency diathermy current applied across a loop mounted on the hand-held trigger of the resectoscope.
We report in this study our 5 years experience of TURP in College of Medical sciences and Teaching hospital , Bharatpur, Nepal.

\section{Materials and Methods}

The medical records of all patients who underwent TURP by single surgeon for diagnosed case of BPH between January 2007 and December 2011 were analyzed retrospectively at urology unit, College of Medical Sciences, Bharatpur, Nepal. Exclusion criteria were previous prostate or urethral surgery and voiding disorders not related to benign prostatic hyperplasia (BPH) (eg, neurogenic bladder disorder), if indicated; prostate carcinoma was excluded by biopsy. Pre operative findings of digital rectal examination, symptoms, urine routine examination, urine culture, serum Prostate specific antigen(PSA), trans abdominal ultrasound, maximum flow rate (Qmax), post void residual volume (PRV). International Prostate Symptom Score (IPSS) along with other variables as operative time, amount of tissue removed, post operative irrigation time requirement of postoperative blood transfusion, duration of requirement of indwelling catheter postoperatively, duration of hospitalization, complications associated with these surgeries and follow up IPSS at 1 year was evaluated, recorded in a proforma, analyzed by SPSS 10 and reviewed in the light of literature. We have followed Nesbit's operating technique of TURP and routine urethral dilatation were done in all of our cases.

\section{Results}

In our study we included 330 patients who were diagnosed and treated for BPH by TURP. Mean age and duration of symptoms was $64.88 \pm 3.904$ years(table-1) and 30.7 months respectively. More than 
$70 \%$ of our patients were predominantly having obstructive urinary symptoms(incomplete emptying, intermittency, weak stream and straining) and 170(51.5\%) patients presented in urinary retention with per urethral catheter in situ and this was the most common indication of surgery. Mean size of prostate was $48.33 \pm 15.214$ grams(table-1) by trans abdominal ultrasonography. Volume of prostate was calculated using the prolate ellipse formula and the 3 main diameters of the gland, in which the volume equals 0.52 $\mathrm{X}$ (LXW X H), where $\mathrm{L}$ is the maximum length (craniocaudal dimension), $\mathrm{H}$ is the maximum height (anteroposterior dimension) (both were obtained from the sagittal plane), and $\mathrm{W}$ is the maximum width (transverse dimension; obtained from the transverse plane).. Pre-operative urine culture of 290(87.8\%) cases were sterile and in 40(12.2\%) cases E-coli were isolated which were managed by specific antibiotics. Mean Qmax before surgery was 7.42 $\pm 1.519 \mathrm{ml}$ per second and after 1 year of follow up it was $15.79 \pm 2.617$ ml per seconds(table-2). 68(20.6\%) patients lost to follow up. Mean IPSS before surgery was $27.88 \pm 3.493$ and after 1 year follow up of 262 cases it was 9.71 \pm 3.820 (table-3). The obstructive symptoms improved the most, while irritative symptoms (frequency, urgency and nocturia) improved less just after operation but at one year follow up less than 5\% of patients had irritative urinary symptoms.Mean amount of prostatic chips removed were 41.10 \pm 7.373 percent(table-1) of the weight reported on transabdominal USG. Mean operating time was $40.53 \pm 12.949$ minutes(table-1). Mean duration of post operative per urethral catheterization, bladder imigation with normal saline and total duration of hospital stay was $2.82 \pm 0.622,28.16 \pm 8.895$ and $3.82 \pm 0.622$ days respectively(table-4). Mean duration of bladder neck traction time was $19.90 \pm 5.327$ hours. 12 (3.6\%)patients required post operative blood transfusion,6(1.8\%) cases developed post operative fever, managed by antibiotics, 7(2.12\%) patients developed intraperitoneal fluid extravasation 3 of them were managed by prolonged catheterization of 7 days and in 4 patients suprapubic and intraperitoneal drain were kept for three days. 8(2.42\%) cases(chart-1) required post operative bladder wash following clot retention. 2(0.67\%) cases(chart-1) turned up again one week after discharge with clot retention and UTI who were managed by bladder wash and antibiotics. Another 3(0.9\%)cases(chart-1) presented two years after surgery with thinning of urinary stream and on evaluation found to have bladder neck contracture, managed by bladder neck incision. Partial temporary incontinence were seen in 17(0.5\%) of our patients managed by anticholinergic drugs. It is to be worth mentioned that most of the complications occurred in first 50 cases and as we grow in our experience complication rate decreased drastically. In last 200 case we had only one case of intraperitoneal leak which was managed conservatively and another case developed post operative clot retention. We also noticed that resection volume of the prostate increased and the resection time decreased after our 50 case of TURP. No case of TUR syndrome was seen in our series and there was no mortality. 
A Agarwal et al. Transurethral resection of prostate - a five year experience..

Table-1

$\begin{array}{lccccc} & \text { N } & \text { Minimum } & \text { Maximum } & \text { Mean } & \text { Std. Deviation } \\ \text { AGE (years) } & 330 & 56 & 74 & 64.88 & 3.904 \\ \text { VOLUME OF PROSTATE(grams) } & 330 & 23 & 82 & 48.33 & 15.214 \\ \text { OPERATING TIME(min) } & 330 & 20 & 74 & 40.53 & 12.949 \\ \text { \% OF TISSUE REMOVED } & 330 & 26 & 58 & 41.10 & 7.373\end{array}$

Table-2

$\begin{array}{lccccc} & \text { N } & \text { Minimum } & \text { Maximum } & \text { Mean } & \text { Std. Deviation } \\ \text { Qmax -pre op } & 165 & 5 & 11 & 7.42 & 1.519 \\ \text { Qmax-12 months } & 262 & 11 & 22 & 15.79 & 2.617 \\ \text { Valid N(listwise) } & 130 & & & & \end{array}$

Table-3

$\begin{array}{lccccc} & \text { N } & \text { Minimum } & \text { Maximum } & \text { Mean } & \text { Std. Deviation } \\ \text { PSS-pre op } & 330 & 20 & 34 & 27.88 & 3.493 \\ \text { IPSS-12months } & 262 & 4 & 17 & 9.71 & 3.820 \\ \text { Valid N(listwise) } & 262 & & & & \end{array}$

Table-4

$\begin{array}{lccccc} & \text { N } & \text { Minimum } & \text { Maximum } & \text { Mean } & \text { Std. Deviation } \\ \text { UB-IRRIGATION(hours) } & 330 & 14 & 48 & 28.16 & 8.895 \\ \text { TRATCTION TIME (hours) } & 330 & 12 & 28 & 19.90 & 5.327 \\ \text { CATHETERIZATION TIME(days) } & 330 & 2 & 4 & 2.82 & 0.622 \\ \text { HOSPITAL STAY(days) } & 330 & 3 & 5 & 3.82 & 0.622 \\ \text { Valid N(listwise) } & 330 & & & & \end{array}$

Chart-1. Complications and their management after TURP

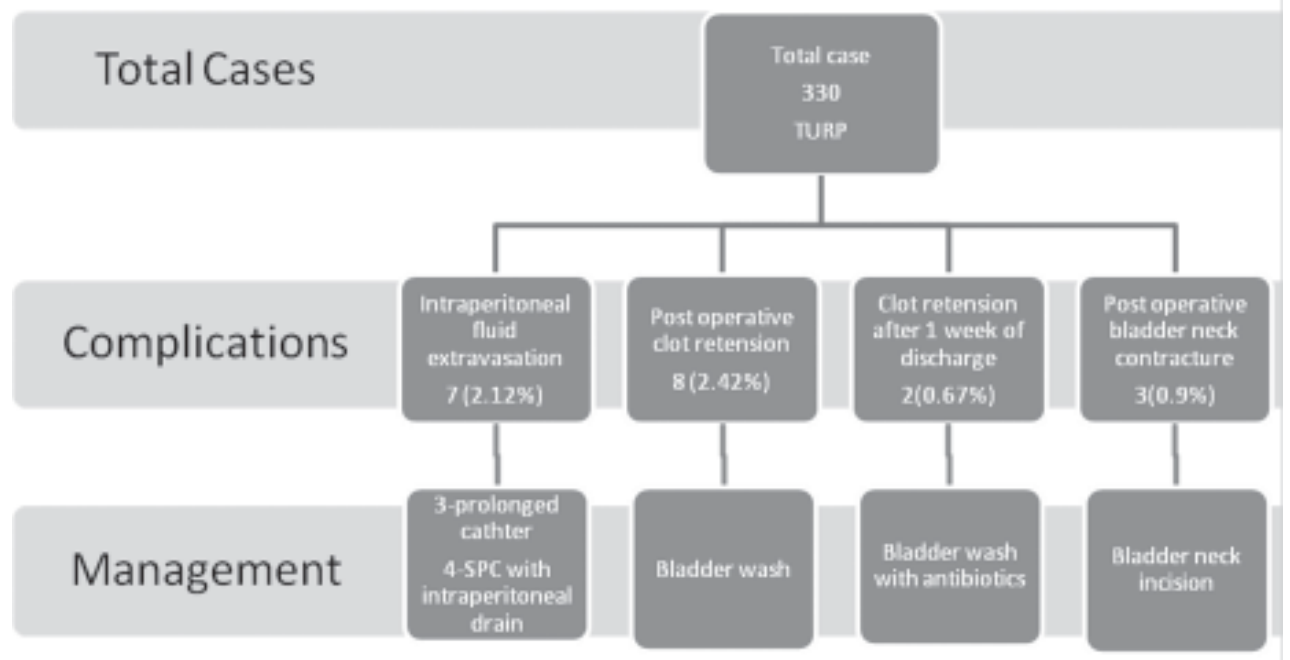




\section{Discussion}

Lower urinary tract symptoms(LUTS) from BPH is a common disorder that affects the majority of men above 50 years of age significantly affecting the quality of life (QOL) of patients. ${ }^{4}$ For most of the patients having severe symptoms and/or with complications due to $\mathrm{BPH}$, TURP is still considered a "gold standard"procedure. ${ }^{5}$ This study showed that most of the patients presented lately with severe symptoms (IPSS > 20) associated with poor quality of life. More than $50 \%$ of the patients in our study presented with urinary retention after failed catheter free trial and large size prostate( $>40$ grams). Around $70.0 \%$ of the patients had combination of one or more complications including acute urinary retention, chronic retention, haematuria or obstructive uropathy requiring indwelling Foley's catheter till the time of surgery. Relieving the obstruction by resection of enlarged adenoma significantly improves the outcome. The resected tissue weight was less than half of that reported by trans- abdominal USG in our series. Hakenberg et al ${ }^{6}$ confirmed that there were no significant correlation between resected prostatic volume with symptom improvement, bother scores and residual urinary volume postoperatively. IPSS has been accepted as a yardstick in measuring the severity of symptoms. Change in the preoperative (at the time of presentation) and postoperative (after recovery from operation) IPSS indicates effectiveness of the surgery-performed in a patient. ${ }^{7}$ In our study, mean preoperative IPSS of patients was 27.88 which is slight higher as compared to other series that ranges from 19.5-22.3 $3^{7,8-11}$ After TURP, there were significant improvement in IPSS(mean 9.71) after one year of follow up. The obstructive symptoms (incomplete emptying, intermittency, weak stream and straining) improved the most, while irritative symptoms (frequency, urgency and nocturia) improved less, post operatively after catheter free trial, indicating that irritative symptoms are less responsive to TURP. Bruskewitz et al $^{12}$ assessed long term (3 year) effect of TURP on obstructive and irritative symptoms and confirmed that TURP had a larger effect on voiding than on filling symptoms. We found that most of the patients had improvement of IPSS by more than 10 units and those with greater preoperative IPSS (>20) gained the most symptomatic benefit. Chuang et $\mathrm{al}^{7}$ showed that decrease in IPSS of more than 7 points predicts subjectively perceptible symptomatic improvement with high sensitivity while good outcome was defined as decrease in IPSS by 10 or more. Since the change in IPSS strongly correlates with preoperative IPSS, the preoperative IPSS seems to be the best predictor of postoperative symptomatic outcome. Hakenberg et $\mathrm{al}^{13}$ reported that a threshold for transurethral prostatectomy of a preoperative IPSS of 17 would be more appropriate. Other parameters like operating time, hospital stay and post operative irrigation time were comparable to other series. ${ }^{9,12}$

\section{Conclusion}

Most of the patients presents late with marked obstructive symptoms and large prostate glands in this part of Nepal. The urinary symptoms in patients with BPH significantly improved after TURP and those patients having severe symptoms gained the most. The complication rates following TURP decreases as experience grow and after a experience of 50 TURP they are almost none. So 50 TURP can be set as benchmark for the beginners. It was also noticed that resection volume of the prostate increased and the resection time decreased significantly after 50 case of TURP. 
A Agarwal et al. Transurethral resection of prostate - a five year experience...

\section{References}

1. R.C.G.Russell, N.S.Williams, C.J.K.Bulstrode. Baliley and Love's Short Practice of Surgery, 24ed: India: Edward Arnold Ltd; 2004;1370-80.

2. A.F.Olumi, J.P.Richie. Sabiston Textbook of Surgery, 18ed, volume2: India: Elsevier; 2008: 2257-2272

3. J.M.Fitzpatrick. Will laser replace TURP for the treatment of Benign Prostatic Hyperplasia. The Lancet. 2000; 356:357

4. K.F.Quek, C.S.Loh, W.Y.Low et al. Quality of life assessment before and after transurethral resection of the prostate in patients with lower urinary tract symptoms. World J Urol 2001; 19: 358-64.

5. Littlejohn, O.Joe, A.Mohamed et al. Transurethral resection of the prostate: the new old standard. Current Opinion Urol 2002; 12: 19-23.

6. O.Hakenberg, C.Helke, A.Manseck et al. Is there a relationship between the amount of tissue removed at transurethral resection of the prostate and clinical improvement in benign prostatic hyperplasia. Eur Urol 2001; 39: 412-7.

7. F.P.Chuang, S.S.Lee, S.T.Wu et al. Change in International Prostate Symptom Score after transurethral prostatectomy in Taiwanese men with benign prostate hyperplasia: Use of these changes to predict the outcome. Arch Androl 2003; 49: 129-37.

8. C.C.Liu, C.J.Wang, S.P.Huang et al. Relationships between American Urological Association symptom index, prostate volume, and diseasespecific quality of life question in patients with benign prostatic hyperplasia. Kaohsiung J Med Sci 2004; 20: 273-8.

9. G.V.Perez, P.A.Peris, A.A.R.Botella et al. Retrospective study conducted on 408 TURPs performed in our center over the time. Actas Urol Esp1997; 21: 206-11.

10. P.Arvind, R.Mahesh, M.Mihir et al. Natural history of lower urinary tract symptoms: preliminary report from a community-based Indian study. Brit J Urol Int'l 2004; 94: 332-4.

11. S.J.Chai, C.T.Heng, S.P.Chan et al. Correlation of intravesical protrusion with bladder outlet obstruction. Brit J Urol Int'l 2003; 91: 371-4.

12. R.Bruskewitz, E.Larsen, P.Madsen et al. 3-year follow-up of urinary symptoms after transurethral resection of the prostate. $J$ Urol 1986; 136: 6135.

13. O.W.Hakenberg, C.B.Pinnock, V.R.Marshall. Does evaluation with the International Prostate Symptom Score predict the outcome of transurethral resection of the prostate? J Urol 1997; 158: 94-9. 